\title{
Heavy-Ion Microbeam Irradiation Induces Bystander Killing of Human Cells
}

\author{
Nobuyuki Hamada ${ }^{1,3,4 \dagger}$, Takamitsu Hara ${ }^{1,3,4}$, Motoko Omura-Minamisawa ${ }^{5}$, Meinan $\mathrm{Ni}^{4}$, Tomoo Funayama ${ }^{4}$, \\ Tetsuya Sakashita ${ }^{4}$, Sakura Sora ${ }^{1,3,4}$, Takashi Nakano ${ }^{2,4}$ and Yasuhiko Kobayashi ${ }^{1,3,4}$ \\ ${ }^{1}$ Department of Quantum Biology, ${ }^{2}$ Department of Radiation Oncology, and ${ }^{3}$ The 21st Century Center of Excellence \\ (COE) Program for Biomedical Research Using Accelerator Technology, Gunma University Graduate School of Medi- \\ cine, Gunma 371-8511, Japan. \\ ${ }^{4}$ Microbeam Radiation Biology Group, Quantum Beam Science Directorate, Japan Atomic Energy Agency (JAEA), \\ Gunma 370-1292, Japan. \\ ${ }^{5}$ Department of Radiology, Yokohama City University Graduate School of Medicine, Kanagawa 236-0004, Japan.
}

\begin{abstract}
Significant evidence indicates that ionizing radiation causes biological effects in nonirradiated bystander cells having received signals from directly irradiated cells. There is little information available hitherto as to the bystander effect of energetic heavy ions; however, our previous work has shown that in confluent cultures of normal human fibroblast AG01522 cells, targeted exposure of $0.0003 \%$ of cells to microbeams of $18.3 \mathrm{MeV} / \mathrm{u}{ }^{12} \mathrm{C}$ $(103 \mathrm{keV} / \mu \mathrm{m})$ and $13.0 \mathrm{MeV} / \mathrm{u}^{20} \mathrm{Ne}(375 \mathrm{keV} / \mu \mathrm{m})$ ions can similarly cause almost $10 \%$ decreases in the clonogenic survival, and twofold increments in the incidence of apoptosis whose temporal kinetics varies between irradiated and bystander cells. Using this experimental system, here we further report that bystander responses of AG01522 cells to $17.5 \mathrm{MeV} / \mathrm{u}{ }^{20} \mathrm{Ne}$ ions $(294 \mathrm{keV} / \mu \mathrm{m})$ are consistent with those to $18.3 \mathrm{MeV} / \mathrm{u}{ }^{12} \mathrm{C}$ and $13.0 \mathrm{MeV} / \mathrm{u}{ }^{20} \mathrm{Ne}$ ions. We also demonstrate that such bystander-induced reductions in the survival are less pronounced and occur independently of Bcl-2 overexpression in human cervical cancer HeLa cells.
\end{abstract}

\section{Introduction}

Ionizing radiation-induced bystander effects have been demonstrated in a variety of endpoints such as genetic and epigenetic changes, apoptosis, inactivation of cellular clonogenic potential, activation of signaling pathways, and delayed effects in their progeny, which occur in nonirradiated bystander cells that have received signals from directly irradiated cells (Chaudhry, 2006; Little, 2006; Mothersill \& Seymour, 2006; Prise et al., 2006; Morgan \& Sowa, 2007; Kovalchuk \& Baulch, 2008). Proposed mechanisms of the bystander effect involve gap junctional intercellular communication (GJIC), reactive oxygen/nitrogen species, secreted soluble factors, lipid rafts, and calcium fluxes (Azzam et al., 2004; Mothersill \& Seymour, 2004; Hamada et al., 2007).

Ample evidence has accumulated that biological effectiveness differs with the linear energy transfer (LET) of radiation. During long-term interplanetary manned explorations, astronauts are exposed to space radiation, which includes energetic heavy ions and other high-LET radiations. Physical dosimetric analysis has estimated that the dose rate on the International Space Station or in

\footnotetext{
Article ID: 082202005

Original paper

Received: May 8, 2008

Accepted: August 26, 2008

${ }^{\dagger}$ To whom correspondence should be addressed: Department of Quantum Biology, Division of Bioregulatory Medicine, Gunma University Graduate School of Medicine, 1233 Watanuki-machi, Takasaki, Gunma 370-1292, Japan. Tel.: +81-(0)27-346-9542; Fax.: +81-(0)27-346-9688; Email: hamada@med.gunma-u.ac.jp
}

a space shuttle is about 150 -fold greater than that on the Earth's surface (Doke et al., 1995). A strategy to protect normal tissue against detrimental effects of heavy ions is therefore necessary. Whilst extensive evidence indicates that heavy ions are more cytotoxic and genotoxic to irradiated cells than low-LET photons like X-rays and $\gamma$-rays (Blakely \& Kronenberg, 1998; Cucinotta, \& Durante, 2006; Hamada, 2009), heavy ion-induced bystander response is incompletely characterized. Less irradiated cells should coexist with more nonirradiated counterparts in a population exposed to a lower dose of higher-LET heavy ions, so that an elucidation of the effects arising not merely in irradiated cells but in their bystander cells would be important to delineate the mechanism of action of heavy ions.

We recently reported that in confluent cultures of normal human fibroblast AG01522 cells, targeted irradiation of $0.0003 \%$ of cells with microbeams of 18.3 $\mathrm{MeV} / \mathrm{u}{ }^{12} \mathrm{C}(103 \mathrm{keV} / \mu \mathrm{m})$ and $13.0 \mathrm{MeV} / \mathrm{u}{ }^{20} \mathrm{Ne}(375$ $\mathrm{keV} / \mu \mathrm{m})$ ions similarly led to almost $10 \%$ reductions in the clonogenic survival, and twofold rises in the incidence of apoptosis whose temporal kinetics varies between irradiated and bystander cells (Hamada et al., 2008a). Using this experimental system, here we further show that bystander responses of AG01522 cells to 17.5 $\mathrm{MeV} / \mathrm{u}^{20} \mathrm{Ne}$ ions $(294 \mathrm{keV} / \mu \mathrm{m})$ are consistent with those to $18.3 \mathrm{MeV} / \mathrm{u}{ }^{12} \mathrm{C}$ and $13.0 \mathrm{MeV} / \mathrm{u}{ }^{20} \mathrm{Ne}$ ions (Hamada et al., 2008a). We also demonstrate that such bystanderinduced decreases in the survival are less manifested and occur independently of Bcl-2 overexpression in human cervical cancer HeLa cells. 


\section{Materials and Methods}

\section{Cell culture}

AG01522D primary normal human diploid fibroblasts were obtained and passaged as previously mentioned (Hamada et al., 2006). AG01522 cells at passages 7-9 were inoculated at $1 \times 10^{4} \mathrm{cells} / \mathrm{cm}^{2}$, replenished on days 4, 7 and 9, and used for irradiation experiments on day 11. This protocol for preparing confluent densityinhibited cultures has been reported to synchronize 95-98\% of the cells in $G_{0}$ and $G_{1}$ phases, and also to maximize intercellular interactions like GJIC (Azzam et al., 2000, 2001). Bcl-2 cells (human cervical cancerderived HeLa cells that stably overexpress Bcl-2) and Neo cells (neomycin resistant gene-expressing HeLa cells), generous gifts from Dr. M. Miura (The University of Tokyo, Japan), were established (Shiraiwa et al., 1997; Nakashima et al., 2000) and subcultured (Hamada et al., 2008 b) as previously described. Neo and Bcl-2 cells were seeded at $1.1 \times 10^{5}$ cells $/ \mathrm{cm}^{2}$ in the absence of G418, and cultured for $48 \mathrm{~h}$, at which time cultures reached confluence and were used for irradiation experiments. All cell cultures were maintained at $37^{\circ} \mathrm{C}$ in a humidified atmosphere of $5 \% \mathrm{CO}_{2}$ in air except where otherwise specified.

\section{$\gamma$-ray irradiation}

Cell monolayers cultured on $25-\mathrm{cm}^{2}$ tissue culture flasks were exposed to ${ }^{60} \mathrm{Co} \gamma$-rays at a dose rate of $2 \mathrm{~Gy} /$ min at room temperature, followed by incubation at $37^{\circ} \mathrm{C}$ in $95 \%$ air $/ 5 \% \mathrm{CO}_{2}$ (Hamada et al., 2006).

\section{Heavy-ion irradiation}

Targeted microbeam irradiation of cell subpopulations (referred hereafter to as microirradiation) was performed using collimated microbeams installed at TIARA (Takasaki Ion Accelerators for Advanced Radiation Application) facilities of Japan Atomic Energy Agency (JAEA), for which the setup and irradiation procedure have been described (Kobayashi et al., 2004; Funayama et al., 2008a, 2008b). Paraffin with a melting temperature of $60-62^{\circ} \mathrm{C}$ (Wako, Osaka, Japan) was used to glue the 25-mm-diameter and 200- $\mu \mathrm{m}$-thick Thermanox coversplip (Nalge Nunc, Roychester, NY) onto a 35-mmdiameter polystyrene dish whose bottom has a $12-\mathrm{mm}$ diameter center hole (Asashi Techno Glass, Chiba, Japan). The assembled microbeam dish (a schematic diagram depicted in Fig. 1) was immersed in $70 \%$ ethanol bath for $1 \mathrm{~h}$, exposed to UVC light for $3 \mathrm{~h}$, and then used for cell inoculation. Considering that roughly $80 \%$ of the particle fluence collimated through a $20-\mu$ m-diameter microaperture was confined to the area of central $20-\mu \mathrm{m}$ circle around which the remaining $20 \%$ was scattered to the area of $15-\mu \mathrm{m}$-wide annulus (Sugimoto et al., 2006), we refer to the unit of the target number herein as the site, rather than the cell. For all the experiments, 10 particles of three different types of heavy ions (physical properties listed in Table 1) were delivered to each of 1,5 and 25 sites with a matrix distribution of $3 \mathrm{~mm} \times 3$

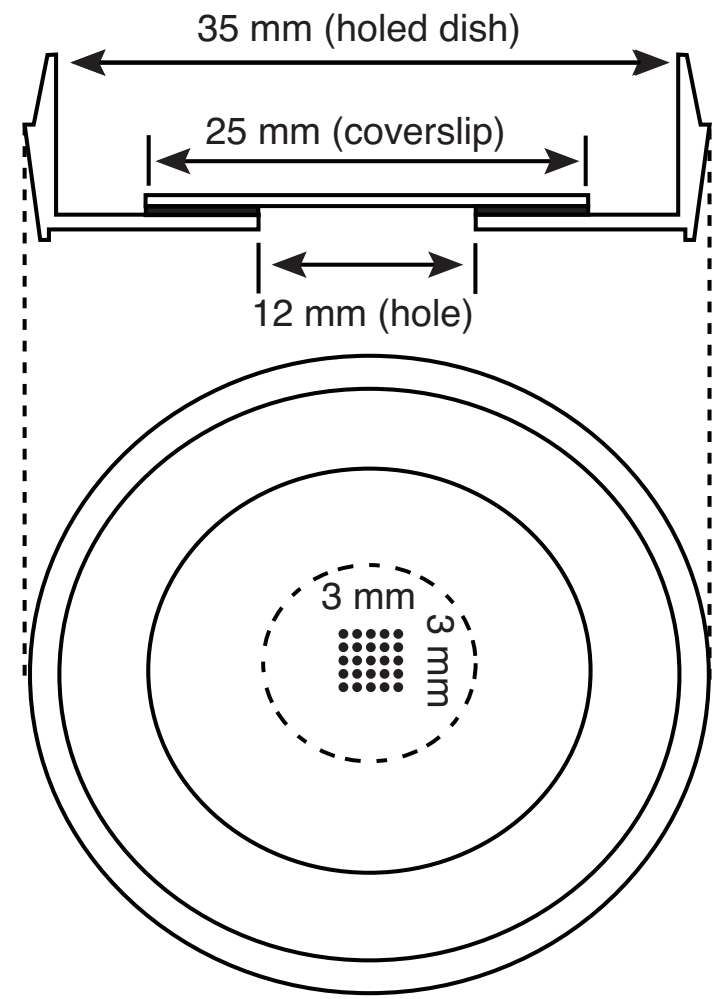

Fig. 1. Diagrammatic presentation of the microbeam dish in lateral and top-down view. The dish was constructed by gluing coverslip and the holed dish. Cells populated throughout the area of the bottom of the dish. Each of 1 (a middle point), 5 (fourcorner and middle points) or 25 sites (all points) with a matrix distribution of $3 \mathrm{~mm} \times 3 \mathrm{~mm}$ square area was microirradiated with 10 particles.

$\mathrm{mm}$ area in the center of the dish (Hamada et al., 2008a). For confluent AG01522 cells, $1.1 \times 10^{6} \pm 8.2 \times 10^{4}$ cells populated in a $35-\mathrm{mm}$ microbeam dish at the time of irradiation, so that the fraction of hit cells among the whole population was estimated to be $0.0003 \%$ when a single site was targeted. Likewise, for confluent cultures of Neo $\left(2.7 \times 10^{6} \pm 2.7 \times 10^{5}\right.$ cells/dish $)$ and Bcl- 2 cells $\left(2.7 \times 10^{6} \pm 2.2 \times 10^{5}\right.$ cells/dish $)$, the fraction of hit cells was estimated to be $0.0002,0.0009$ and $0.005 \%$ when 1,5 and 25 sites were targeted, respectively. In these situations, the vast majority of the cells could be hence considered as bystander cells, and contribution of the effects induced in hit cells to the overall response should be negligible.

Conventional broadfield irradiation was conducted using broadbeams as described (Hamada et al., 2006, $2008 \mathrm{c}$ ). Cell monolayers cultured on $60-\mathrm{mm}$ dishes were exposed to three different types of heavy ions (properties listed in Table 2). The LET at the cell surface was calculated according to the kinetic energy loss, assuming water equivalence. Dose (Gy) was calculated as fluence (number of ion particles $\left./ \mathrm{cm}^{2}\right) \times$ LET $(\mathrm{keV} / \mu \mathrm{m}) \times 1.6 \times$ $10^{-9}$. 
Table 1 Physical properties of heavy-ion microbeams

\begin{tabular}{ccc}
\hline Ion species & LET $(\mathrm{keV} / \mu \mathrm{m})$ & Dose (cGy) to a target cella \\
\hline $18.3 \mathrm{MeV} / \mathrm{u}{ }^{12} \mathrm{C}$ & 103 & 12 \\
$17.5 \mathrm{MeV} / \mathrm{u}^{20} \mathrm{Ne}$ & 294 & 34 \\
$13.0 \mathrm{MeV} / \mathrm{u}^{20} \mathrm{Ne}$ & 375 & 44 \\
\hline
\end{tabular}

The dose (cGy) given by a traversal of maximal 10 particles through a single target cell was calculated as $160 \times$ LET $(\mathrm{keV} /$ $\mu \mathrm{m}) \times$ fluence (number of ion particles $/ \mu \mathrm{m}^{2}$ ), which was further divided by the average size of the whole cell $\left(1370 \mu \mathrm{m}^{2}\right)$, for confluent AG01522 cells.

Conditioned medium from cell monolayers was harvested just prior to heavy-ion irradiation, and the dishes were thereafter covered with $8-\mu$ m-thick Kapton polyimide film (DuPont-Toray, Tokyo, Japan) to keep the cells hydrated, followed by irradiation at room temperature. The conditioned medium was transferred back to the dishes soon after irradiation, and the cultures were then incubated at $37^{\circ} \mathrm{C}$ in $95 \%$ air $/ 5 \% \mathrm{CO}_{2}$. For all the experiments, control cells were sham-irradiated and manipulated in parallel with the test cells.

\section{Cell survival}

Cell survival was determined by the clonogenic survival assay as mentioned (Hamada et al., 2006, 2008d). In brief, confluent cultures were replated within $1 \mathrm{~h}$ postirradiation into $100-\mathrm{mm}$ dishes (AG01522 cells) or $60-\mathrm{mm}$ dishes ( $\mathrm{Neo}$ and $\mathrm{Bcl}-2$ cells) in quadruplicate at numbers estimated to produce 50-80 clonogenic colonies per dish. After incubation for 12-13 days (AG01522 cells) or 10 days (Neo and Bcl-2 cells), cultures were fixed in methanol and stained with crystal violet. Only colonies containing more than 50 cells were scored as survivors.

\section{TUNEL assay}

Apoptosis was detected by the terminal deoxynucleotidyl transferase (TdT)-mediated dUTPbiotin nick-end labeling (TUNEL) method (Gavrieli et al., 1992), using the ApopTag Plus Peroxidase In Situ Apoptosis Detection kit (Millipore, Billerica, MA) as described (Hamada et al., 2008a, 2008e). Briefly, cell monolayers grown on coverslips were fixed in $1 \%$ paraformaldehyde and methanol, and permeabilized in $0.5 \%$ Triton $\mathrm{X}-100$. Afterward, the coverslips were reacted with $3 \%$ hydrogen peroxide, TdT enzyme, and peroxidase-conjugated anti-digoxigenin antibody. Positive TUNEL staining was visualized with diaminobenzidine, followed by counterstain with $0.5 \%$ methyl green. The cells were observed with an Olympus BX60 microscope after mounting, where 1000 or more cells were analyzed for each sample. Hoechst 33342 staining yielded apoptotic indices similar to those of TUNEL staining (Kakizaki et al., 2006).

\section{Statistical analysis}

Data were calculated as the means and standard deviations of three or four repeated experiments unless otherwise stated. Statistical comparisons between groups were made by Student's $t$-test, and a $p$ value of 0.05 or less was considered to be significant.

\section{Results}

\section{Bystander response of normal fibroblasts}

First, to assess the survival of irradiated AG01522 cells, broadbeam-irradiated confluent cultures were reseeded for colony formation (Fig. 2A). The relative biological effectiveness calculated relative to the $10 \%$ survival dose $\left(D_{10}\right)$ of $\gamma$-rays (5.1 Gy) was 3.9, 3.4 and 2.7 for $18.3 \mathrm{MeV} / \mathrm{u}{ }^{12} \mathrm{C}, 17.5 \mathrm{MeV} / \mathrm{u}{ }^{20} \mathrm{Ne}$ and $13.0 \mathrm{MeV} /$ $\mathrm{u}^{20} \mathrm{Ne}$ ions, respectively. Subsequently, to examine the survival of bystander AG01522 cells, a single site was targeted with 10 particles under conditions where particle(s) traversed only $0.0003 \%$ of the cells. Microirradiation caused nearly $10 \%$ reductions in the survival regardless of ion species (Fig. 2B).

Second, $D_{10}$-exposed cultures were evaluated for apoptosis. Fig. 3A illustrates that the apoptotic incidence in irradiated cells escalated with time at least up to $72 \mathrm{~h}$ postirradiation. Apoptotic frequency following exposure to $18.3 \mathrm{MeV} / \mathrm{u}{ }^{12} \mathrm{C}, 17.5 \mathrm{MeV} / \mathrm{u}^{20} \mathrm{Ne}$ and 13.0 MeV/u ${ }^{20} \mathrm{Ne}$ ions was elevated 2.3-, 2.1- and 1.7fold at $24 \mathrm{~h}$ postirradiation, and 3.5-, 3.3- and 3.0-fold at $72 \mathrm{~h}$ postirradiation, respectively over the control level. Next, bystander-induced apoptosis was examined. Microirradiation of a single site with 10 particles resulted in increased yields of apoptotic cells (Fig. 3B). The apoptotic index following microirradiation with 18.3 $\mathrm{MeV} / \mathrm{u}{ }^{12} \mathrm{C}, 17.5 \mathrm{MeV} / \mathrm{u}{ }^{20} \mathrm{Ne}$ and $13.0 \mathrm{MeV} / \mathrm{u}{ }^{20} \mathrm{Ne}$ ions increased 2.4-, 2.2- and 2.0-fold, respectively at $24 \mathrm{~h}$ postirradiation over the control level, but decreased

Table 2 Physical properties of heavy-ion broadbeams

\begin{tabular}{ccccc}
\hline \multirow{2}{*}{ Ion species } & \multirow{2}{*}{ LET $(\mathrm{keV} / \mu \mathrm{m})$} & \multirow{2}{*}{$D_{10}(\mathrm{~Gy})^{\mathrm{a}}$} & \multicolumn{2}{c}{ No. of particles traversed through ${ }^{\mathrm{b}}$} \\
\cline { 4 - 5 } & & 1.3 & A nucleus & A whole cell \\
\hline $18.3 \mathrm{MeV} / \mathrm{u}^{12} \mathrm{C}$ & 108 & 1.5 & 4.8 & 103 \\
$17.5 \mathrm{MeV} / \mathrm{u}^{20} \mathrm{Ne}$ & 321 & 1.9 & 4.5 & 40 \\
$13.0 \mathrm{MeV} / \mathrm{u}^{20} \mathrm{Ne}$ & 437 & 37 \\
\hline
\end{tabular}

a Survival curves illustrated in Fig. 2A were fitted against the means for three or four independent experiments to the exponential equation $y=\exp (-k x)$ where $y, x$ and $k$ are surviving fraction, dose and slope, respectively. $D_{10}$ was calculated as [In (1/0.1)]/k. Cultures were exposed to above-mentioned doses of broadbeams for the experiments demonstrated in Fig. $3 \mathrm{~A}$.

${ }^{b}$ The Poisson-distributed mean number of particles that traversed each nucleus and whole cell was calculated as $D_{10}(\mathrm{~Gy}) /[0.16 \times \mathrm{LET}$ $(\mathrm{keV} / \mu \mathrm{m})]$, which was further multiplied by the average size of the nucleus $\left(165 \mu \mathrm{m}^{2}\right)$ and the whole cell $\left(1370 \mu \mathrm{m}^{2}\right)$, respectively, for confluent AG01522 cells. 
A

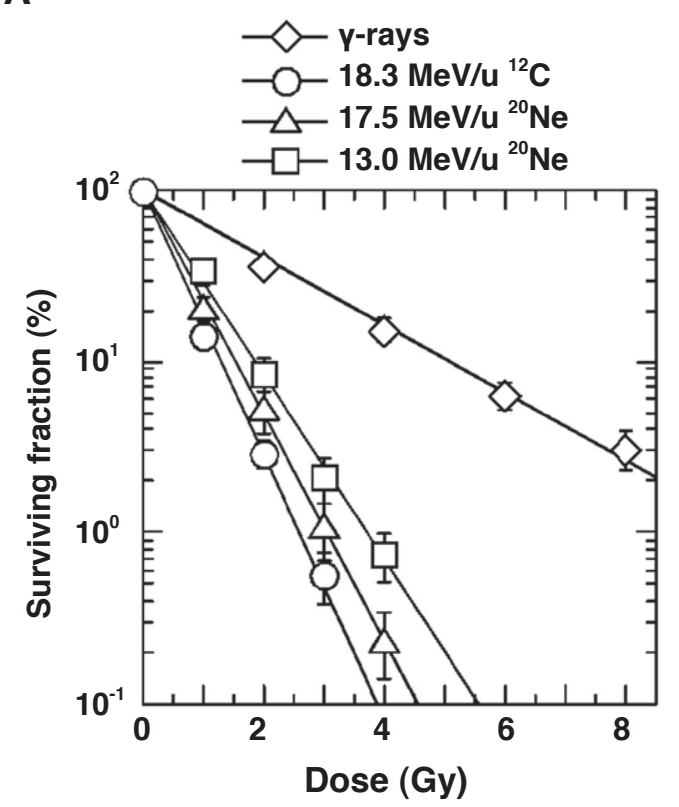

B

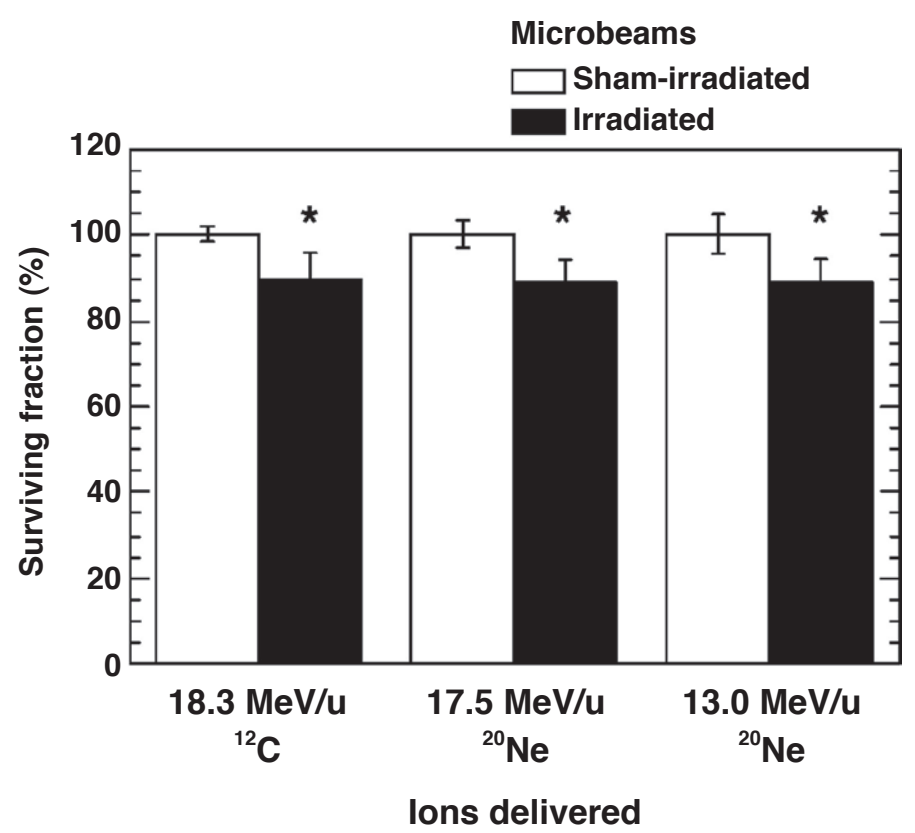

Fig. 2. (A) The clonogenic survival of broadbeam-irradiated AG01522 fibroblasts. Confluent cultures were exposed to $Y$-rays (open diamonds), $18.3 \mathrm{MeV} / \mathrm{u}{ }^{12} \mathrm{C}$ (open circles), $17.5 \mathrm{MeV} / \mathrm{u}^{20} \mathrm{Ne}$ (open triangles), or $13.0 \mathrm{MeV} / \mathrm{u}{ }^{20} \mathrm{Ne}$ ions (open squares). (B) The clonogenic survival of microirradiated AG01522 fibroblasts. A single site was targeted with 10 particles of three different microbeams (solid columns) or sham-irradiated (open columns). Within $1 \mathrm{~h}$ postirradiation, cultures were reinoculated for colony formation. The data are presented as the means and standard errors of three or four independent experiments with quadruplicate measurements. ${ }^{*} p<0.05$ compared with corresponding sham-irradiated controls. The data for $18.3 \mathrm{MeV} / \mathrm{u}{ }^{12} \mathrm{C}$ and $13.0 \mathrm{MeV} / \mathrm{u}{ }^{20} \mathrm{Ne}$ ions were from Hamada et al. (2008a).

at $48 \mathrm{~h}$ postirradiation nearly to the control level. The timescale of apoptosis induction thus varied between irradiated and bystander cells. The apoptotic index in sham-irradiated controls remained unchanged during the time course $(p>0.2)$.

\section{Impact of Bcl-2 overexpression on the bystander response}

Bcl-2 is an antiapoptotic factor that inhibits mitochondrial apoptotic pathways, whose overexpression are found in nearly half of human cancers and associated with radioresistance (Belka \& Budach, 2002; Wang et al., 2003). We previously showed that Bcl-2 cells express ninefold higher levels of Bcl-2 proteins and are more resistant to $\gamma$-rays than Neo cells (Hara et al., 2005; Hamada et al., 2008e), and that there is no statistically significant difference in population doubling time and plating efficiency between sham-irradiated Neo and Bcl-2 cells (Hamada et al., 2008b, 2008e). To assess the impact of Bcl-2 overexpression on the bystander effect for the survival, 10 particles was delivered to each of 1,5 and 25 sites in situations whereby particle(s) traversed only $0.0002,0.0009$ and $0.005 \%$ of the cells, respectively. Figure 4 illustrates that microirradiation of 25 sites led to around $10 \%$ decreases in the survival, regardless of ion species and Bcl-2 overexpression. However, the difference between 5 sites-targeted and sham-irradiated cultures was statistically insignificant whilst there was a slight tendency toward reduced survival (Fig. 4): the same held true for microirradiation of a single site (data not shown).

\section{Discussion}

We recently reported that targeted exposure of a single site in confluent cultures of AG01522 cells to 18.3 MeV/u ${ }^{12} \mathrm{C}$ and $13.0 \mathrm{MeV} / \mathrm{u}{ }^{20} \mathrm{Ne}$ ions inactivates clonogenic potential, and induces a transient apoptotic response, delayed p53 phosphorylation, and gene expression changes at a genome-wide level (Hamada et al., 2008a; Iwakawa et al., 2008). Similar to our previous data for $18.3 \mathrm{MeV} / \mathrm{u}{ }^{12} \mathrm{C}$ and $13.0 \mathrm{MeV} / \mathrm{u}$ ${ }^{20} \mathrm{Ne}$ ions (Hamada et al., 2008a), we found herein that microirradiation of a single site with $17.5 \mathrm{MeV} / \mathrm{u}{ }^{20} \mathrm{Ne}$ ions also led to nearly $10 \%$ reductions in the survival (Fig. 2B) and twofold increments in the apoptotic incidence (Fig. 3B) in bystander AG01522 cells.

Growing evidence indicates that the neighbors of surviving progeny exhibit bystander responses (Nagar \& Morgan, 2005), and that the progeny of bystander cells show delayed phenotypes (Lorimore et al., 2005; Bowler et al., 2006). It is hence possible that death of plated bystander cells (e.g., via apoptosis as shown in Fig. 3B) and delayed death of their descendants contribute to 
A
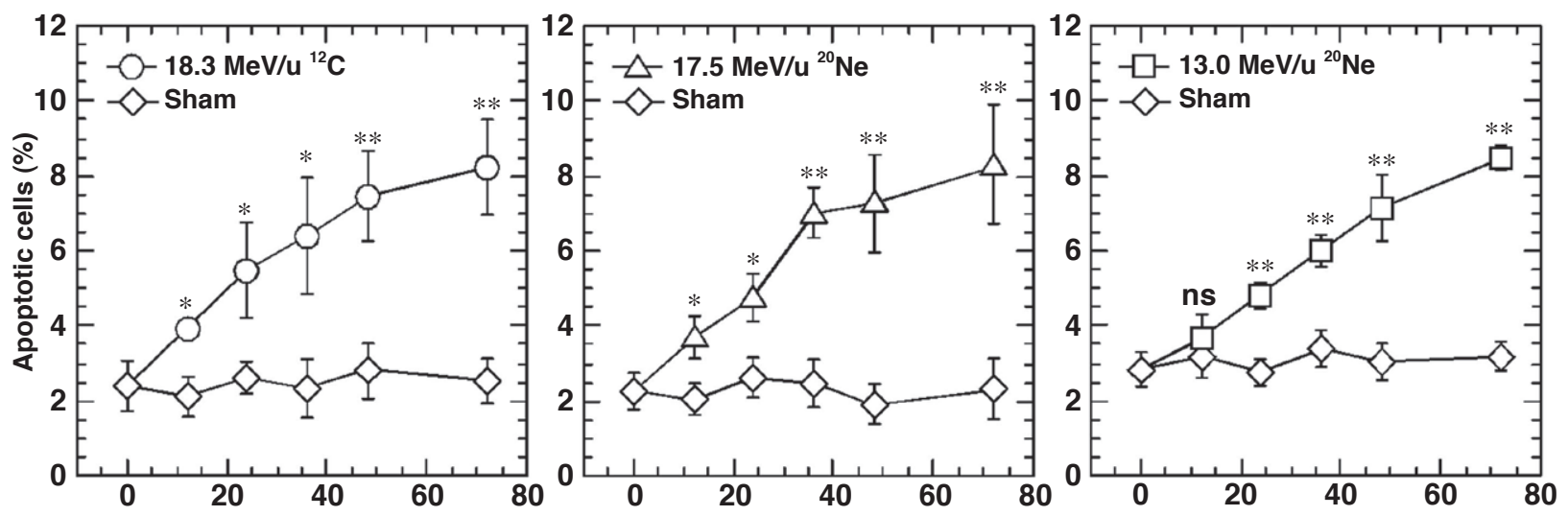

Hours after broadbeam irradiation

B
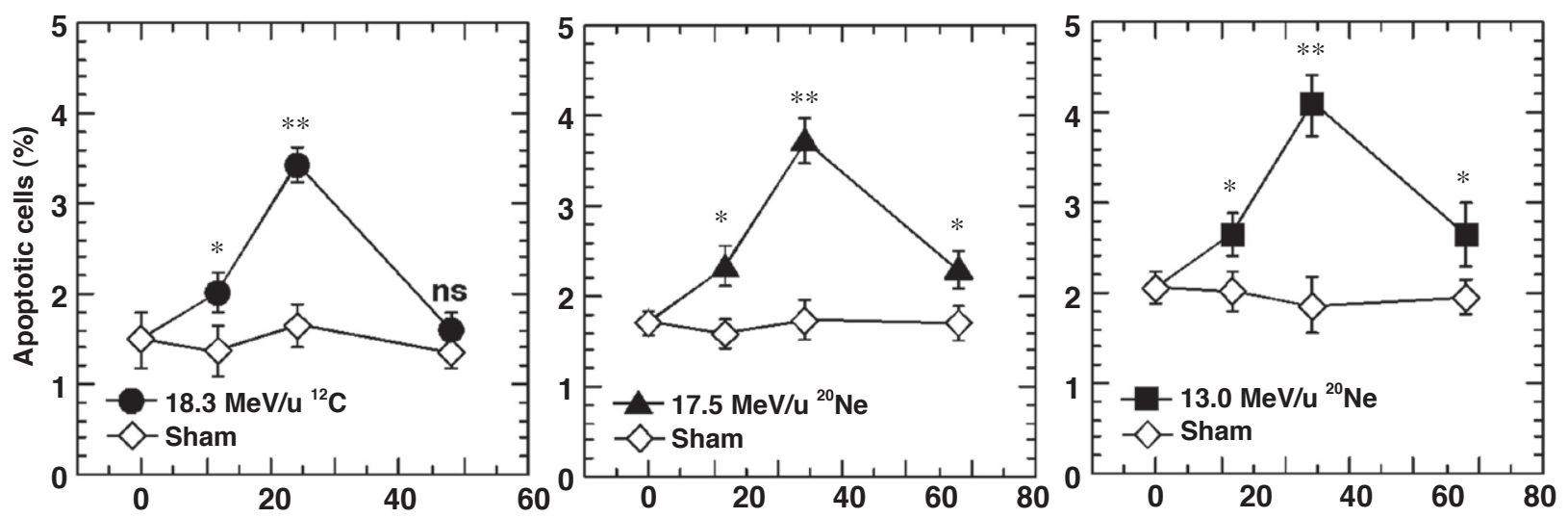

Hours after microbeam irradiation

Fig. 3. (A) Apoptosis induction in broadbeam-irradiated AG01522 fibroblasts. Cultures were fixed at 12, 24, 36, 48 and $72 \mathrm{~h}$ after irradiation with $D_{10}$ (doses listed in Table 2). (B) Apoptosis induction in microirradiated AG01522 fibroblasts. Cultures were fixed at 12 , 24 and $48 \mathrm{~h}$ after irradiation of a single site with 10 particles. Thereafter, fixed cells were assessed for apoptosis. The data represent the means and standard deviations for three or four independent experiments, where 1000 or more cells were analyzed for each specimen. ${ }^{*} 0.01 \leq p<0.05 ;{ }^{* *} p<0.01$ compared with sham-irradiated controls (open diamonds) at each time point. ns, not significant. The data for $18.3 \mathrm{MeV} / \mathrm{u}^{12} \mathrm{C}$ and $13.0 \mathrm{MeV} / \mathrm{u}^{20} \mathrm{Ne}$ ions were from Hamada et al. (2008a).

bystander-induced reductions in the survival (Figs. 2B and 4). Our previous work has shown clonal morphotypic heterogeneity and delayed loss of clonogenicity in colonies arising from heavy ion-irradiated AG01522 cells (Hamada et al., 2006, 2008d). To address whether this is also the case for colonies arising from bystander cells, further experiments are ongoing.

Microirradiation of $0.005 \%$, but not $0.0009 \%$ or less, significantly reduced the survival of $\mathrm{Neo}$ and $\mathrm{Bcl}-$ 2 cells (Fig. 4), whereas microirradiation of $0.0003 \%$ significantly reduced the survival of AG01522 cells (Fig. 2B). This is indicative of attenuated bystander responses of Neo and Bcl-2 cells. First, whereas AG01522 cells are proficient in GJIC that mediates the transmission of signals from irradiated to bystander cells (Azzam et al., 2001), HeLa cells (a parental cell line of Neo and Bcl2 cells) are deficient in GJIC (Hamada et al., 2003), suggesting that HeLa cells lack GJIC-mediated bystander responses. Second, whilst AG01522 cells are diploid and have functional p53 that participates in a highLET radiation-induced $\mathrm{G}_{1}$ checkpoint (Azzam et al., 2000), HeLa cells are multiploid and have impaired p53 function (Scheffner et al., 1990), indicating that HeLa cells are less susceptible to loss of clonogenicity. Such differences may potentially explain attenuated bystander responses of Neo and $\mathrm{Bcl}-2$. Taken together, little difference in the survival of microirradiated $\mathrm{Neo}$ and Bcl-2 cells implies that at least in HeLa cells, bystander cell killing occurs via Bcl-2-independent mechanism(s), such as non-mitochondrial apoptotic pathways.

Several studies have documented that DNA breakage and p53 phosphorylation occur in bystander fibroblasts at delayed times than in irradiated fibroblasts (Sokolov et al., 2005; Hamada et al., 2008a). There is also evidence 


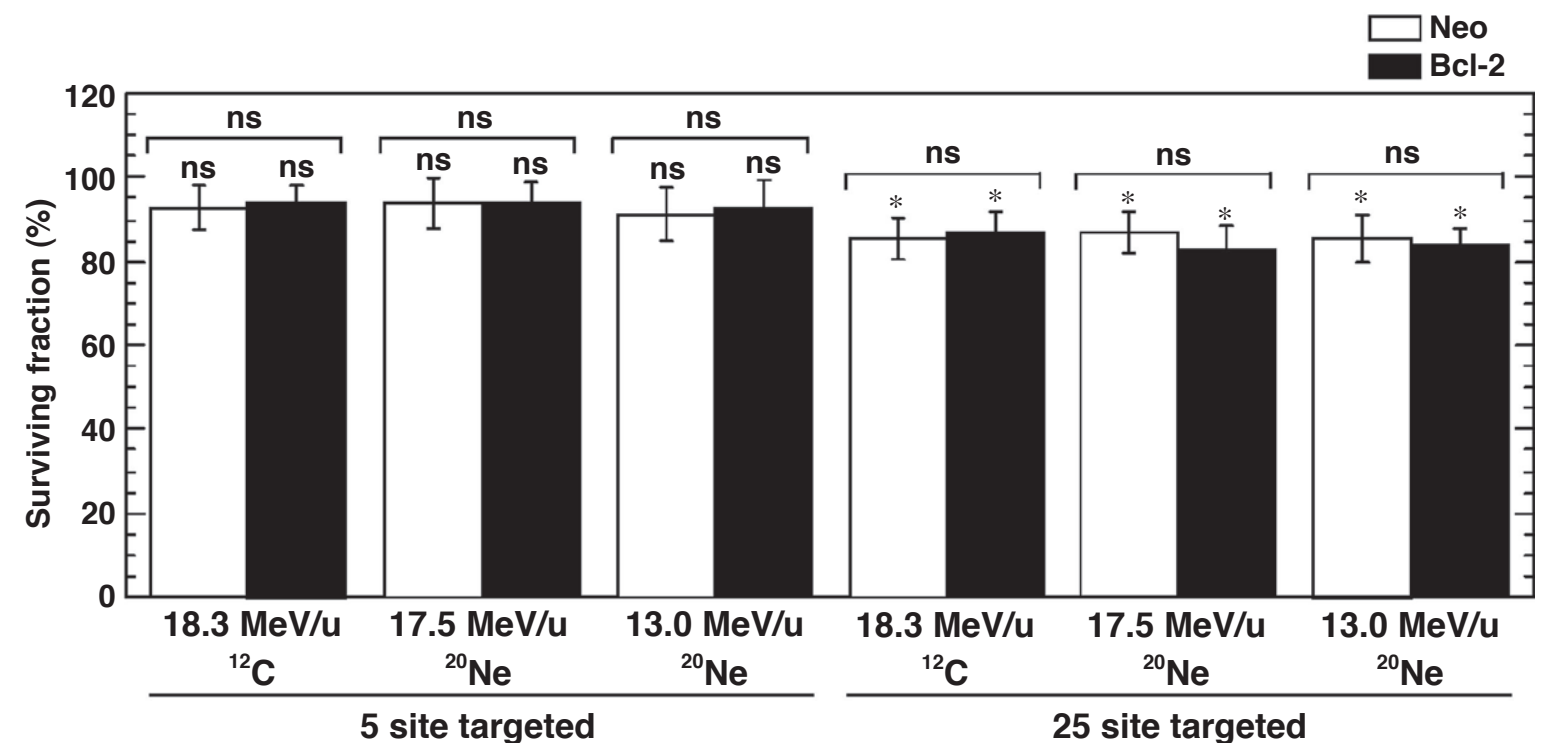

Fig. 4. The clonogenic survival of microirradiated $\mathrm{Neo}$ (open columns) and Bcl-2 cells (filled columns). Cultures were reseeded for colony formation within $1 \mathrm{~h}$ after exposure of 1,5 or 25 sites each to 10 particles. The data shown are the means and standard errors of three independent experiments with quadruplicate measurements. ${ }^{*} p<0.05$ compared with corresponding sham-irradiated controls. ns, nonsignificant.

that while irradiated fibroblasts display both transient and permanent $\mathrm{G}_{1}$ arrest, bystander fibroblasts undergo transient but not permanent $\mathrm{G}_{1}$ arrest (Azzam et al., 2000), indicating that most of bystander-induced DNA breakage may be reparable. This implies that such an event might cause temporally distinct apoptotic response in irradiated and bystander cells (Fig. 3B).

We found that reductions in the survival (Figs. 2B and 4) and apoptosis induction (Fig. 3B) in bystander cells are independent of LET. Other recent studies have also shown such LET independence (Shao et al., 2003; Fournier et al., 2007; Kanasugi et al., 2007; Yang et al., 2007). However, as regards the bystander effect of photons and heavy ions, we recently showed the difference in the types of chromosome aberrations, but very little difference in the total aberration yields (Kanasugi et al., 2007). Furthermore, there has been a report showing potential LET dependence (Shao et al., 2002). Taken together, biological effectiveness of heavy ions in irradiated cells has been known to vary with ion species even at comparable LET (Tsuruoka et al., 2005; Suzuki et al., 2006). Therefore, an elucidation of LETand ion species dependency of the bystander effect needs further extensive studies.

In conclusion, we have demonstrated, on one hand, that the bystander effect of heavy ions is manifested as the reduced survival and a transient apoptotic response in normal fibroblasts. Such responses might be a protective mechanism that would avert or minimize further expansion of aberrant cells, and thus maintain cellular homeostasis. A deeper comprehension of the early-and late-occurring effects of heavy ions may reduce uncertainties in the health risk assessment for astronauts. On the other, we have also demonstrated that attenuated bystander responses occur independently of Bcl-2 overexpression in cervical cancer cells. Enhancing bystander response of tumor cells would provide a novel potential radiotherapeutic regimen where lower doses and/or smaller tumor target volume could be irradiated (Lumniczky \& Safrany, 2006; Hamada et al., 2007).

\section{Acknowledgements}

The authors are indebted to Dr. Masayuki Miura (The University of Tokyo, Japan) for providing the cells. Thanks are also due to Drs. Takehiko Kakizaki, Yoshihiro Hase, and the crew at the TIARA of JAEA for help with the heavy-ion irradiation. This work was supported by a Grant-in-Aid for the 21st Century COE Program for Biomedical Research Using Accelerator Technology from the Ministry of Education, Culture, Sports, Science and Technology (MEXT) of Japan, and by the Budget of Nuclear Research of the MEXT based on the screening and counseling by the Atomic Energy Commission of Japan.

\section{References}

Azzam, E.I., de Toledo, S.M., Waker, A.J. and Little, J.B. (2000) High and low fluences of $\alpha$-particles induce a $G_{1}$ checkpoint in human diploid fibroblasts. Cancer Res., 60, 2623-2631.

Azzam, E.I., de Toledo, S.M. and Little, J.B. (2001) Direct evidence for the participation of gap junction-mediated intercellular communication in the transmission of damage signals from $\alpha$-particle irradiated to nonirradiated cells. Proc. Natl. Acad. Sci. U.S.A., 98, 473-478.

Azzam, E.I., de Toledo, S.M. and Little, J.B. (2004) Stress signaling from irradiated to non-irradiated cells. Curr. 
Cancer Drug Targets, 4, 53-64.

Belka, C. and Budach, W. (2002) Anti-apoptotic Bcl-2 proteins: structure, function and relevance for radiation biology. Int. J . Radiat. Biol., 78, 643-658.

Blakely, E.A. and Kronenberg, A. (1998) Heavy-ion radiobiology: new approaches to delineate mechanisms underlying enhanced biological effectiveness. Radiat. Res., 150, S126-S145.

Bowler, D.A., Moore, S.R., Macdonald, D.A., Smyth, S.H., Clapham, P. and Kadhim, M.A. (2006) Bystander-mediated genomic instability after high LET radiation in murine primary haemopoietic stem cells. Mutat. Res., 597, 50-61.

Chaudhry, M.A. (2006) Bystander effect: biological endpoints and microarray analysis. Mutat. Res., 597, 98-112.

Cucinotta, F.A. and Durante, M. (2006) Cancer risk from exposure to galactic cosmic rays: implications for space exploration by human beings. Lancet Oncol., 7, 431-435.

Doke, T., Hayashi, T., Kikuchi, J., Hasebe, N., Nagaoka, S., Kato, M. and Badhwar, G.D. (1995) Real time measurement of LET distribution in the IML-2 Space Lab (STS-65). Nucl. Instr. Meth., B365, 524-532.

Fournier, C., Becker, D., Winter, M., Barberet, P., Heiss, M., Fischer, B., Topsch, J. and Taucher-Scholz, G. (2007) Cell cycle-related bystander responses are not increased with LET after heavy-ion irradiation. Radiat. Res., 167, 194-206.

Funayama, T., Wada, S., Yokota, Y., Fukamoto, K., Sakashita, T., Taguchi, M., Kakizaki, T., Hamada, N., Suzuki, M., Furusawa, Y., Watanabe, H., Kiguchi, K. and Kobayashi, Y. (2008a) Heavy-ion microbeam system at JAEA-Takasaki for microbeam biology. J. Radiat. Res., 49, 71-82.

Funayama, T., Hamada, N., Sakashita, T. and Kobayashi, Y. (2008b) Heavy-ion microbeams - development and applications in biological studies. IEEE Trans. Plasma Sci., 36, 1432-1440.

Gavrieli, Y., Sherman, Y. and Ben-Sasson S.A. (1992) Identification of programmed cell death in situ via specific labeling of nuclear DNA fragmentation. J. Cell Biol., 119, 493-501.

Hamada, N. (2009) Recent insights into the biological action of heavy-ion radiation. J. Radiat. Res., 50, in press (doi: 10.1269/jrr.08070).

Hamada, N., Kodama, S., Suzuki, K. and Watanabe, M. (2003) Gap junctional intercellular communication and cellular response to heat stress. Carcinogenesis, 24, 1723-1728.

Hamada, N., Funayama, T., Wada, S., Sakashita, T., Kakizaki, T., $\mathrm{Ni}$, M. and Kobayashi, Y. (2006) LET-dependent survival of irradiated normal human fibroblasts and their descendents. Radiat.Res., 166, 24-30.

Hamada, N., Matsumoto, H., Hara, T. and Kobayashi, Y. (2007) Intercellular and intracellular signaling pathways mediating ionizing radiation-induced bystander effects. J. Radiat. Res., 48, 87-95.

Hamada, N., Ni, M., Funayama, T., Sakashita, T. and Kobayashi Y. (2008a) Temporally distinct response of irradiated normal human fibroblasts and their bystander cells to energetic heavy ions. Mutat. Res., 639, 35-44.

Hamada, N., Hara, T., Omura-Minamisawa, M., Funayama, T.,
Sakashita, T., Sora, S., Nakano, T. and Kobayashi Y. (2008b) The survival of heavy ion-irradiated Bcl-2 overexpressing radioresistant tumor cells and their progeny. Cancer Lett., 268, 76-81.

Hamada, N., Kataoka, K., Sora, S., Hara, T., OmuraMinamisawa, M., Funayama, T., Sakashita, T., Nakano, T. and Kobayashi Y. (2008c) The small-molecule Bcl2 inhibitor HA14-1 sensitizes cervical cancer cells, but not normal fibroblasts, to heavy-ion radiation. Radiother. Oncol., 89, 227-230.

Hamada, N., Hara, T., Funayama, T., Sakashita, T. and Kobayashi, Y. (2008d) Energetic heavy ions accelerate differentiation in the descendants of irradiated normal human diploid fibroblasts. Mutat. Res., 637, 190-196.

Hamada, N., Hara, T., Omura-Minamisawa, M., Funayama, T., Sakashita, T., Sora, S., Yokota, Y., Nakano, T. and Kobayashi Y. (2008e) Energetic heavy ions overcome tumor radioresistance caused by overexpression of Bcl-2. Radiother. Oncol., 89, 231-236.

Hara, T., Omura-Minamisawa, M., Chao, C., Nakagami, Y., Ito, M. and Inoue, T. (2005) Bcl-2 inhibitors potentiate the cytotoxic effects of radiation in Bcl-2 overexpressing radioresistant tumor cells. Int. J. Radiat. Oncol. Biol. Phys., 61, 517-528.

Iwakawa, M., Hamada, N., Imadome, K., Funayama, T., Sakashita, T., Kobayashi Y. and Imai, T. (2008) Expression profiles are different in carbon ion-irradiated normal human fibroblasts and their bystander cells. Mutat. Res., 642, 5767.

Kakizaki, T., Hamada, N., Wada, S., Funayama, T., Sakashita, T., Hohdatsu, T., Sano, T., Natsuhori, M., Kobayashi, Y. and Ito, N. (2006) Distinct modes of cell death by ionizing radiation observed in two lines of feline T-lymphocytes. $J$. Radiat. Res., 47, 237-243.

Kanasugi, Y., Hamada, N., Wada, S., Funayama, T., Sakashita, T., Kakizaki, T., Kobayashi, Y. and Takakura, K. (2007) Role of DNA-PKcs in the bystander effect after low- or high-LET irradiation. Int. J. Radiat. Biol., 83, 73-80.

Kobayashi, Y., Funayama, T., Wada, S., Furusawa, Y., Aoki, M., Shao, C., Yokota, Y., Sakashita, T., Matsumoto, Y., Kakizaki, T. and Hamada, N. (2004) Microbeams of heavy charged particles. Biol. Sci. Space, 18, 235-240.

Kovalchuk, O. and Baulch, J.E. (2008) Epigenetic changes and nontargeted radiation effects - is there a link? Environ. Mol. Mutagen., 49, 16-25.

Little, J.B. (2006) Cellular radiation effects and the bystander response. Mutat. Res., 597, 113-118.

Lorimore, S.A., McIlrath, J.M., Coates, P.J. and Wright, E.G. (2005) Chromosomal instability in unirradiated hemopoietic cells resulting from a delayed in vivo bystander effect of $\gamma$ radiation. Cancer Res., 65, 5668-5673.

Lumniczky, K. and Safrany, G. (2006) Cancer gene therapy: combination with radiation therapy and the role of bystander cell killing in the anti-tumor effect. Pathol. Oncol. Res., 12, 118-124.

Morgan, W. F. and Sowa, M.B. (2007) Non-targeted bystander effects induced by ionizing radiation. Mutat. Res., 616, 159164. 
Mothersill, C. and Seymour, C.B. (2004) Radiation-induced bystander effects - implications for cancer. Nat. Rev. Cancer, 4, 158-164.

Mothersill, C. and Seymour, C.B. (2006) Radiation-induced bystander effects and the DNA paradigm: an "out of field" perspective. Mutat.Res., 597, 5-10.

Nagar, S. and Morgan, W.F. (2005) The death-inducing effect and genomic instability. Radiat. Res., 163, 316-323.

Nakashima, T., Miura, M. and Hara, M. (2000) Tetrocarcin A inhibits mitochondrial functions of Bcl-2 and suppresses its anti-apoptotic activity. Cancer Res., 60, 1229-1235.

Prise, K.M., Folkard, M., Kuosaite, V., Tartier, L., Zyuzikov, N. and Shao, C. (2006) What role for DNA damage and repair in the bystander response? Mutat. Res., 597, 1-4.

Scheffner, M., Werness, B.A., Huibregtse, J.M., Levine, A.J. and Howley, P.M. (1990) The E6 oncoprotein encoded by human papillomavirus type 16 and 18 promotes the degradation of p53. Cell, 63, 1129-1136.

Shao, C., Furusawa, Y., Aoki, M., Matsumoto, H. and Ando, K. (2002) Nitric oxide-mediated bystander effect induced by heavy-ions in human salivary gland tumour cells. Int. J. Radiat. Biol., 78, 837-844.

Shao, C., Furusawa, Y., Kobayashi, Y., Funayama, T. and Wada, S. (2003) Bystander effect induced by counted highLET particles in confluent human fibroblasts: a mechanistic study. FASEB J., 17, 1422-1427.

Shiraiwa, N., Okano, H. and Miura, M. (1997) Bcl-2 prevents TNF- and Fas-induced cell death but does not inhibit initial processing of caspase-3. Biomed. Res., 18, 405-411.

Sokolov, M.V., Smilenov, L.B., Hall, E.J., Panyutin, I.G., Bonner, W.M. and Sedelnikova, O.A. (2005) Ionizing radiation induces DNA double-strand breaks in bystander primary human fibroblasts. Oncogene, 24, 7257-7265.

Sugimoto, T., Dazai, K., Sakashita, T., Funayama, T., Wada, S., Hamada, N., Kakizaki, T., Kobayashi, Y. and Higashitani, A. (2006) Cell cycle arrest and apoptosis in Caenorhabditis elegans germline cells following heavy-ion microbeam irradiation. Int. J. Radiat. Biol., 82, 31-38.

Suzuki, M., Tsuruoka, C., Kanai, T., Kato, T., Yatagai, F. and Watanabe, M. (2006) Cellular and molecular effects for mutation induction in normal human cells irradiated with accelerated neon ions. Mutat. Res., 594, 86-92.

Tsuruoka, C., Suzuki, M., Kanai, T. and Fujitaka, K. (2005) LET and ion species dependence for cell killing in normal human skin fibroblasts. Radiat. Res., 163, 494-500.

Wang, S., Yang, D. and Lippman, M.E. (2003) Targeting Bcl2 and $\mathrm{Bcl}-\mathrm{X}_{\mathrm{L}}$ with nonpeptidic small-molecule antagonists. Semin. Oncol., 30, 133-142.

Yang, H., Anzenberg, V. and Held, K.D. (2007) The time dependence of bystander responses induced by iron-ion radiation in normal human skin fibroblasts. Radiat. Res., 168, 292-298. 